\begin{tabular}{c|c|c|c|c|} 
DOI: http://dx.doi.org/10.21276/ap.covid19.2021.10.1.8 \\
Annals of Phytomedicine: An International Journal \\
http://www.ukaazpublications.com/publications/index.php \\
Print ISSN : 2278-9839
\end{tabular}

\title{
The urge for early detection and effective therapy against COVID-19 fungal co- infection: A retrospective study
}

\author{
Mohammed Sarosh Khan
}

Department of Basic Medical Sciences, College of Medicine, Prince Sattam Bin Abdulaziz University, Al-Kharj-11942, Saudi Arabia

\begin{tabular}{l} 
Article Info \\
\hline Article history \\
Received 3 May 2021 \\
Revised 21 June 2021 \\
Accepted 22 June 2021 \\
Published Online 30 June 2021
\end{tabular}

\section{Keywords}

COVID-19

Fungal co-infection

Immunosuppression

Diagnosis and treatment methods

Combination therapy

\begin{abstract}
A conspicuous feature of COVID-19 is that the disease has become a pandemic in less than three months. Suppression of immune system, particularly reduction in CD4+T cells and CD8+T cells has led to the coinfection by other microbial pathogens. Among them, fungal co-infections are rarely identified and often ignored. Fungal co-infection has also been reported in MERS, SARS-CoV-1 and other viral infections as influenza. But from the reports of COVID-19, most cases of the fungal infections were observed to be fatal. This raises a serious concern on fungal pathogens causing co-infection in COVID-19. The fungal pathogens causing co-infections were found to be Aspergillus sp., Candida sp., Saccharomyces cerevisiae, Pneumocystis jirovecii, Histoplasma capsulatum, Cryptococcus sp., Coccidioides sp. and Mucormycetes. The unidentified and untreated infection leads to death of the patient. Researchers all over the world are facing several difficulties in identifying and diagnosing fungal co-infections, as early detection and proper treatment can increase the chances of patient survival. The current review summarizes the occurrence of fungal coinfection among COVID-19 patients. The immunological imbalance, diagnosing methods and detailed explanation on fungal pathogens and combination therapy are discussed.
\end{abstract}

\section{Introduction}

In December 2019, the coronavirus disease 2019 (COVID-19) was first identified in Wuhan, China. It quickly spread across mainland China, posing a global challenge. Despite the global containment and promising preventive steps like quarantine efforts and isolation measures, the infection rate of cases about the disease's epidemiological and clinical characteristics has skyrocketed with no approved antiviral drugs available commercially to prevent or treat serious COVID-19 patients (Zhu et al., 2020). Several collective clinical symptoms of the infection have been documented, including dry cough, coryza, myalgia, sore throat, fatigue and dyspnea. However, reports of unusual symptoms and signs have also been observed. In severe cases, malfunctioning of respiratory organs develops, leading to acute respiratory distress syndrome (ARDS), which is characterised by multiorgan failure that affects kidney and cardiac function, as well as death (Li et al., 2020). The causative pathogen, extreme acute respiratory distress syndrome coronavirus2 (SARS-CoV-2) has infected 15,36,32,236 people worldwide and killed 32,15,270 people as of May 4, 2021 (www.cdc.gov).

A conspicuous feature is that COVID-19 has become pandemic in less than three months. The key risk factors for severity and mortality in COVID-19 are older age, diabetes, hypertension, cardiovascular disease and chronic obstructive pulmonary disease. Modern medicine has aided in the prompt detection of SARS-CoV-2, formerly known as the 2019 novel coronavirus and also the discovery of new therapies for SARS-CoV-2, such as lopinavir/ritonavir, chloroquine/

Corresponding author: Dr. Mohammed Sarosh Khan Department of Basic Medical Sciences, College of Medicine, Prince Sattam Bin Abdulaziz University, Al-Kharj-11942, Saudi Arabia E-mail: drsaroshkhan21@gmail.com

Tel.: +96-6564618539

Copyright (c) 2021 Ukaaz Publications. All rights reserved.

Email: ukaaz@yahoo.com; Website: www.ukaazpublications.com hydroxychloroquine, and Remdesivir (Zhang et al., 2020). However, many problems remain unsolved, including a viable strategy for preventing disease dissemination, the collection of suitable clinical samples, the transmission path, viral dynamics, and successful drug therapies. The risk of co-infection with other microbial pathogens resulted in uncertainty of the patients survival. This, however, should be a major concern for clinicians dealing with COVID-19 (Wu et al., 2020).

Researchers all over the world have been facing several difficulties in identifying and diagnosing fungal co-infections. Hence, early detection and effective antifungal therapies to treat fungal infections have acquired a lot of attention in the fight against these important (but often ignored) diseases on a global scale. Furthermore, the treatment of fungal infection costs thousands of dollars per year in both the public and private sectors, which has a significant effect on the economy of healthcare systems around the world (Peng et al., 2021). On analysing all the evidences, the current review focuses on a summary and severity of fungal infections identified in COVID-19 positive patients till now with an emphasis on combination therapy in these patients.

\subsection{Co-infection in influenza, SARS and Middle East respira- tory syndrome (MERS)}

Since co-infections are a common and serious complication of influenza, and it is difficult to rule out the presence of co-infection in a patient with community-acquired pneumonia (CAP) who tests positive for influenza, the american thoracic society (ATS) and the infectious diseases society of america (IDSA) recently released CAP guidelines that recommended initial antimicrobial treatment for adults with CAP who test positive for influenza. Co-infection of bacterial/ fungal pathogens has been observed in MERS and SARS-CoV-1 infections, according to previous reports on serious coronavirus 
infections (Metlay et al., 2019). In a retrospective analysis, 28\% of reports mentioned co-infection in SARS-CoV-1, 6\% among MERS, and $17 \%$ among other coronaviruses. It is well understood that bacterial and fungal co-infections exacerbated viral respiratory infections (influenza), and the SARS outbreak was marked by a high rate of nosocomial transmission of drug-resistant microorganisms (Rawson et al., 2020). These findings elaboratedthe co-infection of bacterial/fungal pathogens with coronaviruses and other respiratory pathogens (Yap et al., 2004).

\subsection{Co-infection in COVID-19}

Until now, the care guidelines for possible co-infections in COVID19 positive patients have been based on the initial guidelines for treating co-infections in patients with serious flu. However, because the clinical entities capable of causing co-infections are expected to be the same for both extreme acute respiratory distress syndrome coronavirus 2 (SARS-CoV-2) and influenza virus infections (Schauwvlieghe et al., 2018), this is an observational assumption. All patients from a Wuhan hospital received empirical antimicrobial treatment, while $93 \%$ received antiviral therapy, according to an early analysis on COVID-19 infections in China (Huang et al., 2020). According to another reports from the Wuhan experience, antiviral, antifungal and antibacterial agents were given to $76 \%, 15 \%$ and $71 \%$ of COVID-19 patients, respectively (Chen et al., 2020). Since the majority of COVID-19 patients in hospitals are receiving intensive medical treatment, such as intubation or mechanical ventilation, they are at risk of contracting hospital infections. Broad-spectrum antibiotics were administered in 75\% of COVID-19 infected patients admitted to intensive care units (ICU) in accordance with this statement. According to the overall meta-analysis, 50\% of COVID19 infections had co-infection, and $8 \%$ had co-infection during hospitalisation (Cox et al., 2020).

In COVID-19 patients with predisposing factors, the frequency of opportunistic fungal infections is significantly higher (e.g., diabetes, mechanical ventilation and cytokine storm). However, owing to the COVID-19 patients complex medical conditions and the improper collection of clinical specimens, the vast majority of fungal infections in this community of patients are misidentified. The presence of fungal co-infection in COVID-19 patients has been shown to have a significant impact on hospitalisation time, disease duration, and mortality (Hughes et al., 2020). In support of this assertion, the researchers have seen an increase in evidence of secondary invasive fungal infections, which result in poor patient outcomes and, as a result, high mortality rates. As a result, this vital fact necessitates a rush to concentrate on various aspects of this emerging disease. Several studies with Aspergillus sp. co-infection with COVID-19 were published, similar to previous findings that showed an association between influenza and invasive pulmonary aspergillosis (Huang et al., 2019).

\subsection{Necessity for diagnosis of fungal co-infection and techniques}

Some fungal diseases have symptoms that are similar to COVID-19, such as fever, cough, and shortness of breath. Critically ill patients, especially those admitted to the intensive care unit (ICU) who needed mechanical ventilation, or those who had longer hospital stays, even up to 50 days, were more likely to develop fungal co-infections (Yang et al., 2020). These fungal co-infections are becoming more common, and they have been linked to serious illness and death. It is important to be aware of the risk of fungal co-infection in order to minimise diagnostic and treatment delays and help avoid serious illness and death from these infections. As a result, it is important to remember that COVID-19 patients, especially those who are seriously ill, may develop new fungal infections in the middle and later stages of the disease. To determine whether a person has a fungal co-infection with COVID-19, laboratory testing is needed (Gangneux et al., 2020).

Histopathology, microscopic observation, and culturing are the traditional methods of diagnosis. These methods can pose unpredictable biosafety risks because the related specimens cannot be inactivated: hence, advanced methods such as molecular identification and serological tests must be used instead (Wang et al., 2020). The identification of blood samples using molecular analysis (qPCR technique) was found to be effective. Serological assays for fungal antigens, such as (1,3)-b-D-glucan (G), galactomannan (GM), and mannan $(\mathrm{Mn})$ tests are often used to diagnose fungal infection (Salehi et al., 2020). If, the result of preliminary findings are positive, a confirmation step is performed with blood biomarkers, such as serum galactomannan and/or serum beta-D-glucan and/or cryptococcal antigenemia for fungal pathogens. The specificity of the $\mathrm{G}$ test in invasive Candida and Aspergillus infection is $70 \%-80 \%$, and the specificity of serum GM detection ranges from $70 \%$ to $80 \%$. Mannan detection has a specificity of $93 \%$. The specificity of combined mannan antigen and antibody detection can be increased to $83 \%$ to 86\% (Ahmad and Khan, 2012).

\subsection{Immunosuppression paves way for fungal co-infection}

The angiotensin-converting enzyme 2 receptor, which is highly expressed on alveolar epithelial cells as well as heart, kidney and intestinal cells, allows SARS-CoV-2 to reach target cells. In the response to viral infections, a variety of innate immune cells (neutrophils and monocytes) and adaptive immune cells (particularly CD4+T cells and CD8+T cells) are involved and COVID-19 is no exception. SARSCoV-2 has been shown to strongly activate the immune system, causing a "cytokine storm" of abnormal cytokine output, particularly in severe cases. Indeed, people with extreme COVID-19 had higher levels of pro-inflammatory cytokines and chemokines in their blood, as well as less $\mathrm{T}$ cells in their peripheral blood, possibly due to lymphocyte aggregation at the infection site (Mehta et al., 2020). This heightened immune response can destroy infected cells, but it can also worsen the disease and cause lung damage. It is worth noting that, in addition to respiratory symptoms, thrombosis and pulmonary embolism have been found in extreme COVID-19 patients. More research is required to identify the molecular players in SARS-CoV-2 pathogenesis, which could lead to the discovery of main targets for reducing or inhibiting the cytokine storm (Yuki et al., 2020).

Candida species and Pseudomonas aeruginosa can colonise mucous membranes and skin in healthy people, and antifungal and antibacterial defences are aided by both innate and adaptive immune cells. The main cellular players are neutrophils, macrophages, dendritic cells, and T- and B-lymphocytes. The first line of protection is the innate immune cells, and the release of inflammatory cytokines and chemokines causes neutrophils to be recruited from the peripheral blood (Jiang, 2016). Dendritic cells play a crucial role in triggering the adaptive immune response. CD4+T helper cells are important adaptive immune cells, with Th17 being the most significant subtype. These cells primarily work at the lung mucosal barrier, producing/releasing interleukin-17 (IL-17), which aids in the 
organisation of B and $\mathrm{T}$ cells into bronchus-associated lymphoid tissue, which is involved in secondary immune responses, as well as the release of antifungal b-defensins. Suppression of the immune system occurs among COVID-19 patients due to the decline in CD4 $+\mathrm{T}$ and $\mathrm{CD} 8+\mathrm{T}$ cells. Patients with IL-17 synthesis or signalling deficiencies tend to be more vulnerable to fungal pathogens. As a result, the incidence and survivability are also reduced (Netea et al., 2015).

In the past, scientists believed that aspergillosis only affected people who had extremely compromised immune systems. However, aspergillosis is becoming more common in patients who do not have a compromised immune system but have serious viral respiratory infections, such as influenza (Lamoth and Calandra, 2018). The activation of antiviral immunity in infected patients host tissue (the lungs are the most commonly affected organs in COVID-19 positive patients) can provide a favourable environment for the establishment, growth, and development of various microorganisms. In persons with active infection induced by the human immunodeficiency virus (HIV), extreme flu, and COVID-19, for example, a significant rise in fungal infections (e.g., candidiasis, aspergillosis, cryptococcosis, pneumocystosis, histoplasmosis) has been identified (Huang et al., 2020).

\subsection{Fungal infections associated with COVID-19 \\ 1.5.1 Aspergillosis}

COVID-19 progression, like extreme flu, causes acute respiratory distress syndrome (ARDS), which puts patients at risk for secondary pulmonary aspergillosis. Aspergillus sp., a filamentous fungus found all over the world, causes this infection. Since Aspergillus spores are commonly found in the atmosphere, they can easily penetrate the airway system and, as a result, invade human lung tissue and/or paranasal sinuses via inhalation. Aspergillus induces a broad variety of infections with a wide range of clinical symptoms, from localised to disseminated disease (Kosmidis and Denning, 2015). Invasive aspergillosis, for example, often affects highly immunocompromised patients as a result of organ transplantation, cancer treatment (due to chemotherapy and/or radiotherapy), neutropenia, and long-term corticosteroid treatment. Furthermore, allergic aspergillosis (e.g., allergic bronchopulmonary aspergillosis, or ABPA) has been linked to asthma exacerbation and bronchitis in people with hyperactive immune systems, as well as cystic fibrosis patients. Even, if detected early and treated with antifungal medication, invasive aspergillosis caused by Aspergillus species (e.g., Aspergillus fumigatus, Aspergillus niger, Aspergillus flavus, Aspergillus terreus) has a mortality rate of 30 to $95 \%$ (Brown et al., 2012).

In people with serious COVID-19, scientists are still investigating aspergillosis. Patients with severe COVID-19 are more likely to develop CAPA (COVID-19 related pulmonary aspergillosis). Since patients may have non-specific symptoms and testing usually involves a specimen from deep inside the lungs, it may be difficult to diagnose. Long-term illness may often turn fatal. Even, if patients with extreme COVID-19 who have deteriorating respiratory function or sepsis do not have classical risk factors for aspergillosis, clinicians should consider the likelihood of aspergillosis. CAPA is diagnosed by taking samples from a patient's lower respiratory tract and testing them for Aspergillus sp. galactomannan antigen and fungal culture (Wang et al., 2020).

CAPA has been recorded in several recent studies. According to some Chinese reports, COVID-19 patients have a high rate of aspergillosis (Arastehfar et al., 2020). In a retrospective analysis from a Wuhan ICU, Aspergillus flavus and Aspergillus fumigatus were isolated from respiratory tract secretions in two out of every seven $(28.6 \%)$ patients with hospital-acquired pneumonia (Yang et al., 2020). In another retrospective study of 85 fatal cases of COVID-19 performed in two Wuhan hospitals, fungal cultures obtained from sputum obtained from 9 patients were confirmed positive in $33.3 \%$ of cases, with 8 (9.4\%), $3(3.5 \%)$, and $2(2.4 \%)$ patients receiving voriconazole, fluconazole, and caspofungin, respectively (Du et al., 2020). However, fungal infections were poorly described in all of the Chinese reports, making it difficult to draw any conclusions. Table 1 shows the detailed case reports of patients coinfected with aspergillosis and severity based on recovery status.

\subsubsection{Candidiasis}

As a consequence of compromised immune system functions, fungal infections caused by yeasts may also occur in patients with ARDS, like COVID-19. Invasive candidiasis is a serious healthcare-associated fungal infection that causes high mortality rates. It is caused by a variety of opportunistic Candida species, the most common of which is Candida albicans and Candida tropicalis. Patients admitted to the hospital for COVID-19 are at risk for healthcare-associated infections (HAIs), such as candidemia, or Candida-related bloodstream infections. In patients with extreme COVID-19, fungal infections resistant to antifungal treatment have also been reported. In patients with serious COVID-19 fungal co-infections, early detection and surveillance for Candida infections and antifungal resistant infections (e.g., Candida auris, azole-resistant Aspergillus) are critical to reducing death from COVID-19 (Pappas et al., 2018).

During COVID-19 pandemic in New York City, USA, Candida sp. was one of the most commonly detected fungi in the bloodstream of patients using central venous catheters. The majority of Candida species recovered from COVID-19 patients, according to recent reports, came from the oropharynx. Oropharyngeal candidiasis is a localised mucous membrane infection characterised by oral epithelial cell invasion and destruction (Nori et al., 2021). During the first COVID-19 pandemic, Candida spp. and other yeasts were isolated from the respiratory tract in $21.4 \%$ of positive cases of co-infection in two hospitals in the United Kingdom (21.4\%) (Hughes et al., 2020).

A retrospective research in Italy looked at the respiratory specimens of COVID-19 patients in the intensive care unit. The results revealed that nearly $52 \%$ of the specimens tested positive for bacteria and fungi (Candida albicans and Candida glabrata) (Intra et al., 2020). Furthermore, the authors of an Iranian study found that Candida albicans was the most common, followed by Candida glabrata (10.7\%), Candida dubliniensis (9.2\%), Candida parapsilosis sensu stricto (4.6\%), Candida tropicalis (3\%), and Pichia kudriavzevii (=C. krusei, $1.5 \%)$ (Salehi et al., 2020). Table 2 shows the prevalence of candidiasis among COVID-19 cases, as well as the severity of the infection based on the patients recovery status. 
Table 1: COVID-19 cases co-infected with Aspergillosis

\begin{tabular}{|c|c|c|c|c|}
\hline Study & City/country & No. of patients & Fungal co-pathogen & Patient status \\
\hline Koehler et al., 2020 & Cologne, Germany & $5 / 19$ & Aspergillus fumigatus & 2 alive; 3 died \\
\hline Lamoth et al., 2020 & Lausanne, Switzerland & $3 / 80$ & Aspergillus fumigatus & 2 alive; 1 died \\
\hline Meijer et al., 2020 & Nijmegen, The Netherlands & 1 & Aspergillus fumigatus & Died \\
\hline García Clemente et al., 2021 & Oviedo, Spain & 2 & $\begin{array}{l}\text { Aspergillus fumigatus } \\
\text { and Aspergillus nidulans }\end{array}$ & 2 alive \\
\hline Nasri et al., 2020 & Isfahan, Iran & 1 & Aspergillosis & Died \\
\hline Trovato et al., 2021 & Catania, Italy & 1 & Aspergillus niger & Died \\
\hline Santana et al., 2020 & Mansus, Brazil & 1 & Aspergillus penicillioides & Died \\
\hline Nasir et al., 2020 & Karachi, Pakistan & $9 / 23$ & Aspergillosis & 4 alive; 5 died \\
\hline Alanio et al., 2020 & Paris, France & 2 & A. fumigatus & 2 died \\
\hline Prattes et al., 2021 & Graz, Austria & 1 & A. fumigatus & Died \\
\hline Lescure et al., 2020 & Paris, France & 1 & A. flavus & Died \\
\hline Rutsaert et al., 2020 & Antwerp, Belgium & 6 & A. fumigatus & 3 death; 3 alive \\
\hline Van Arkel et al., 2020 & Breda, Netherlands & 6 & A. fumigatus & 2 alive; 4 died \\
\hline Antinori et al., 2020 & Milan, Italy & 1 & A. fumigatus & Died \\
\hline Lahmer et al., 2020 & Munich, Germany & 2 & A. fumigatus & 2 died \\
\hline
\end{tabular}

Source: Pubmed and web of knowledge (case reports published till April, 2021).

Table 2: COVID-19 cases co-infected with Candidiasis

\begin{tabular}{|l|l|c|l|l|}
\hline Study & City/country & No. of patients & Fungal co-pathogen & Patient status \\
\hline Seitz et al., 2020 & Vienna, Austria & 1 & Candida glabrata & Died \\
\hline Agrifoglio et al., 2020 & Madrid, Spain & $21 / 139$ & Candidiasis & 12 alive; 9 died \\
\hline Posteraro et al., 2020 & Rome, Italy & 1 & Candida glabrata & Died \\
\hline Sari et al., 2021 & Jakarta, Indonesia & 1 & Candida tropicalis & Alive \\
\hline
\end{tabular}

Source: Pubmed and web of knowledge (case reports published till April, 2021).

Table 3: COVID-19 cases co-infected with Saccharomyces infection

\begin{tabular}{|l|l|c|l|c|}
\hline Study & City/country & No. of patients & Fungal co-pathogen & Patient status \\
\hline Ventoulis et al., 2020 & Ptolemaida, Greece & 2 & Saccharomyces cerevisiae & 2 alive; 0 died \\
\hline Amorim dos Santos et al., 2020 & Brasilia, Brazil & 1 & Saccharomyces cerevisiae & Alive \\
\hline
\end{tabular}

Source: Pubmed and web of knowledge (case reports published till April, 2021).

\subsubsection{Saccharomyces infection}

One of the fungal pathogens found to co-infect is Saccharomyces cerevisiae. However, there are only a few reports on Saccharomyces co-infection, and the severity was found to be mild. Anidulafungin and fluconazole were the most common antifungal drugs used. The organism was discovered to be a poor pathogen, and no deaths have yet been recorded (Nori et al., 2021). Table 3 shows the prevalence of Saccharomyces infection among COVID-19 cases, as well as the severity of the infection based on the patients' recovery status.

\subsubsection{Pneumocystis}

Pneumocystis pneumonia, one of the most common opportunistic fungal infections associated with acquired immunodeficiency syndrome (AIDS) patients, has long been linked to other immunodeficiencies (White et al., 2018). Pneumocystis pneumonia is caused by a fungal pathogen Pneumocystis jirovecii. COVID-19 and Pneumocystis pneumonia have similar clinical characteristics, but this fungal infection is often misdiagnosed. In a case reported by Mang et al., 2020, Pneumocystis pneumonia was diagnosed in a German patient after a chest tomography, revealed slight reticular changes. The presence of Pneumocystis jirovecii in the bronchoalveolar lavage fluid was verified, and the patient was given intravenous trimethoprim-sulfamethoxazole $(20 \mathrm{mg} / \mathrm{kg} / \mathrm{day}$ of trimethoprim) and $50 \mathrm{mg}$ of prednisone (a corticoid drug) daily to prevent adverse immune reactions. Table 4 shows the prevalence of Pneumocystis among COVID-19 cases, as well as the severity of the infection based on the patients recovery status. Table 4 shows the prevalence of Pneumocystis pneumonia among COVID-19 cases, as well as the severity of the infection based on the patients recovery status. 
Table 4: COVID-19 cases co-infected with Pneumocystis

\begin{tabular}{|l|l|c|l|l|}
\hline Study & City/country & No. of patients & Fungal co-pathogen & Patient status \\
\hline Menon et al., 2020 & Massachusetts, United states & 1 & Pneumocystis jirovecii & Alive \\
\hline Jeican et al., 2021 & Cluj-Napoca, Romania & 1 & Pneumocystis jirovecii & Died \\
\hline De Francesco et al., 2020 & Brescia, Italy & 1 & Pneumocystis jirevocii & Died \\
\hline
\end{tabular}

Source: Pubmed and web of knowledge (case reports published till April, 2021).

Table 5: COVID-19 cases co-infected with other fungal pathogens

\begin{tabular}{|c|c|c|c|c|}
\hline Study & City/country & No. of patients & Fungal co-pathogen & Patient status \\
\hline Mehta and Pandey, 2020 & Mumbai, India & 1 & Mucormycosis & Died \\
\hline Basso et al., 2021 & Rio Grande, Brazil & 1 & Histoplasma capsulatum & Alive \\
\hline Chiappe Gonzalez et al., 2020 & Lima, Peru & 1 & Cryptococcus neoformans & Died \\
\hline Shah et al., 2020 & CA, USA & 1 & Coccidioidomycosis & Alive \\
\hline Khatri et al., 2021 & NY, USA & 1 & Mucormycosis & Died \\
\hline Waizel-Haiat et al., 2021 & Mexico City, Mexico & 1 & Mucormycosis & Died \\
\hline
\end{tabular}

Source: Pubmed and web of knowledge (case reports published till April, 2021).

\subsubsection{Other fungal co-infection}

Symptoms offungal pneumonias can resemble COVID-19. Fever, cough, and shortness of breath are symptoms of other fungal infections, such as Valley fever (Coccidioido mycosis), histoplasmosis, and blastomycosis, which are related to COVID-19 and bacterial pneumonias. These fungi can only be found in soil. People are affected by inhaling fungi that are found in the air. If COVID-19 testing is negative, clinicians may accept fungal pneumonias as a potential cause of respiratory illness. It is worth noting that these fungal infections may happen at the same time as COVID-19 (Bertolini et al., 2020; Shah et al., 2020).

Fungal infections like Cryptococcosis and Mucormycosis were also discovered. In a retrospective analysis, $94.2 \%$ of COVID-19 patients were co-infected with one or more respiratory microbial pathogens. Six cases of Mucor (2.5\%) and two cases of Cryptococcus $(0.8 \%)$ were found in COVID-19 infected patients, in addition to the common cases of Aspergillus and Candida species. Fungal infection was found in $29.5 \%$ of all co-infected cases in that study (Zhu et al., 2020). Table 5 shows the prevalence of other fungal infection among COVID19 cases, as well as the severity of the infection based on the patients recovery status.

\subsection{Combination therapy with antifungal antibiotics and its complications}

The initial recommendations for the treatment of possible coinfections in the ATS/IDSA CAP treatment guidelines were made for influenza. Since SARS-CoV-2 infections may have a common clinical entity of co-infection, this recommendation has been used in the treatment of COVID-19 infections and has been documented in previous studies on SARS-CoV-2 infections in China. Beyond the difficulties of treating critically ill patients with a single dangerous infection, such as COVID-19 (for which there are currently no effective drugs), treating critically ill patients with two potentially fatal infections is much more difficult. This situation is exacerbated in the COVID-19 infection scenario, if the co-infection is caused by fungi, since the antifungal arsenal is severely reduced, resulting in dangerous drug interactions, high toxicity, and serious and severe side effects, such as kidney or liver injury.
COVID-19 reports show that a serious viral infection can damage multiple organs on its own (e.g., liver, kidney and heart). When multiple infections were present, such safety issues were even more troublesome. In particular, when COVID-19 patients are combined with fungal infections, particularly those caused by multidrugresistant strains, the situation can become more complicated. Several evolving fungal pathogens have been found to have novel resistance patterns, making available antifungal drugs ineffective in treating these infections, resulting in a classic therapeutic failure (Silva et al., 2019). Antifungal resistance can develop after prolonged clinical exposure to previously active new triazoles (such as posaconazole, voriconazole, and isavuconazole) or echinocandins (such as caspofungin, anidulafungin, and micafungin), resulting in therapy failures. This phenomenon has been reported in the literature and can occur in patients who have been taking antifungal medications for a long time. Therefore, combination therapy with antifungal agents could reduce the severity and prevents from mortality (Chowdhary et al., 2017; Perlin, 2015).

Another factor to consider is the possibility of drug-drug reactions during treatment. For COVID-19 therapy, a variety of medications are currently being studied or used empirically. Many studies highlight the drugs tocilizumab, an interleukin (IL)-6 receptor blocker, and glucocorticoids, which are widely used to inhibit intense and dangerous inflammatory processes. Over-suppression of the immune system, on the other hand, has been shown to favour the emergence of opportunistic fungal infections. In this sense, some reports indicate that tocilizumab should be used with caution in COVID-19 patients because the disease can be exacerbated by it, resulting in complicated pneumonia cases or candidemia episodes. Similarly, other immunomodulatory drugs in development for COVID-19, such as anakinra (recombinant IL-1Ra) and janus kinase (JAK) inhibitors, can predispose patients to pulmonary aspergillosis(Antinori et al., 2020a; Morena et al., 2020).

Antifungal therapeutic failure can be traced back to improper specimen sampling, a scarcity of standard equipment for microbiological analyses, a lack of early identification of fungal elements in contaminated tissue, and a lack of specialist practitioners to accurately 
diagnose the fungal agent (many clinicians disregard fungal infections). Regrettably, this practical picture could have a significant effect on the rising number of COVID-19 positive patients who succumb to fungal infections. In ICU patients with serious COVID-19 associated pneumonia, efforts should be made to investigate cases as quickly as possible to maintain or rule out a diagnosis of invasive fungal infections. Patients with pre-existing risk factors, especiallysolid organ transplant (SOT) recipients, should be given special consideration. Furthermore, since most mycological parameters lack precision but are critical in the diagnosis of fungal superinfections in the ICU, they should be multiplied and carefully examined to avoid overdiagnosis and antifungal therapy overuse (Arastehfar et al., 2020; Cox et al., 2020).

\section{Conclusion}

Most importantly, when secondary fungal infections are suspected, effective antifungal therapy should be started as soon as possible. Continuous monitoring of COVID-19 patients at described risk factors should be performed for early detection and development of fungal co-infections. Since there are only a few groups of systemic antifungal agents, the global emergence of antifungal resistance in fungal pathogens has made treatment more difficult. As most of the fungal co-infections reported are lethal, the continuous monitoring and effective antifungal therapy could save lives of several patients.

\section{Acknowledgements}

The author is grateful to the Deanship of Scientific Research, Prince Sattam bin Abdulaziz University, Al-Kharj, Saudi Arabia for its support in conducting this review and publishing this report.

\section{Conflict of interest}

The author declares that there are no conflicts of interest relevant to this article.

\section{References}

Agrifoglio, A.; Cachafeiro, L.; Figueira, J.C.; Añón, J.M. and García de Lorenzo, A. (2020). Critically ill patients with COVID-19 and candidaemia: We must keep this in mind. J. Mycol. Med., https://doi.org/10.1016/ j.mycmed.2020.101012.

Ahmad, S and Khan, Z. (2012). Invasive candidiasis: A review of nonculturebased laboratory diagnostic methods. Indian J. Med. Microbiol., https://doi.org/10.4103/0255-0857.99482

Alanio, A.; Dellière, S.; Fodil, S.; Bretagne, S. and Mégarbane, B. (2020). Prevalence of putative invasive pulmonary aspergillosis in critically ill patients with COVID-19. Lancet Respir. Med., https://doi.org/10.1016/S22132600(20)30237-X

Amorim dos Santos, J.; Normando, A.G.C.; Carvalho da Silva, R.L.; De Paula R.M.; Cembranel, A.C.; Santos-Silva, A.R. and Guerra, E.N.S. (2020). Oral mucosal lesions in a COVID-19 patient: New signs or secondary manifestations? Int. J. Infect. Dis., https://doi.org/10.1016/j.ijid. 2020.06.012.

Antinori, S.; Bonazzetti, C.; Gubertini, G.; Capetti, A.; Pagani, C.; Morena, V.; Rimoldi, S.; Galimberti, L.; Sarzi-Puttini, P and Ridolfo, A.L. (2020a). Tocilizumab for cytokine storm syndrome in COVID-19 pneumonia: an increased risk for candidemia? Autoimmun. Rev., https://doi.org/ 10.1016/j.autrev.2020.102564

Antinori, S.; Rech, R.; Galimberti, L.; Castelli, A.; Angeli, E.; Fossali, T.; Bernasconi, D.; Covizzi, A.; Bonazzetti, C.; Torre, A.; Carsana, L.; Tonello, C.; Zerbi, P and Nebuloni, M. (2020b). Invasive pulmonary aspergillosis complicating SARS-CoV-2 pneumonia: A diagnostic challenge. Travel Med. Infect. Dis., https://doi.org/10.1016/j.tmaid.2020.101752.
Arastehfar, A.; Carvalho, A.; van de Veerdonk, F.L.; Jenks, J.D.; Koehler, P.; Krause, R.; Cornely, O.A.; Perlin, D.S.; Lass-Flörl, C and Hoenigl, M.;(2020). COVID19 associated pulmonary aspergillosis (CAPA) - from immunology to treatment. J. Fungi, https://doi.org/10.3390/jof6020091.

Basso, R.P.; Poester, V.R.; Benelli, J.L.; Stevens, D.A.; Zogbi, H.E.; Vasconcellos, I.C. da S.; Pasqualotto, A.C and Xavier, M.O. (2021). COVID-19: Associated histoplasmosis in an AIDS patient. Mycopathologia, 186:109-112. https://doi.org/10.1007/s1 1046-020-00505-1.

Bertolini, M.; Mutti, M.F.; Barletta, J.A.E.; Falak, A.; Cuatz, D.; Sisto, A.; Ragusa, M.A.; Fernandez Claros, N.O and Rolón, M.J. (2020). COVID-19 associated with AIDS-related disseminated histoplasmosis: A case report. Int. J. STD AIDS, 31:1222-1224. https://doi.org/10.1177/0956462420 957518 .

Brown, G.D.; Denning, D.W and Levitz, S.M. (2012). Tackling human fungal infections. Science, pp:80-28. https://doi.org/10.1126/Science. 1222236.

Chen, N.; Zhou, M.; Dong, X.; Qu, J.; Gong, F.; Han, Y.; Qiu, Y.; Wang, J.; Liu, Y.; Wei, Y.; Xia, J.; Yu, T.; Zhang, X and Zhang, L. (2020). Epidemiological and clinical characteristics of 99 cases of 2019 novel coronavirus pneumonia in Wuhan, China: A descriptive study. Lancet, 395:507-513. https:/ /doi.org/10.1016/S0140-6736(20)30211-7

Chiappe Gonzalez, A.J.; Montenegro-Idrogo, J.J.; Vargas Vadillo, A.R.; Slee Torres, M.; Vargas Matos, I. and Resurrección Delgado, C.P. (2020). Hospitalacquired SARS-CoV-2 pneumonia in a person living with HIV. Int. J. STD AIDS, 31:1320-1322. https://doi.org/10.1177/095646242095 7528.

Chowdhary, A.; Sharma, C. and Meis, J.F. (2017). Azole-resistant aspergillosis: Epidemiology, molecular mechanisms, and treatment. J. Infect. Dis., 216:S436-S444. https://doi.org/10.1093/infdis/jix210

Cox, M.J.; Loman, N.; Bogaert, D and O'Grady, J. (2020). Co-infections: potentially lethal and unexplored in COVID-19. The Lancet Microbe, 1:e11. https://doi.org/10.1016/s2666-5247(20)30009-4.

De Francesco, M.A.; Alberici, F.; Bossini, N.; Scolari, F.; Pascucci, F.; Tomasoni, G. and Caruso, A. (2020). Pneumocystis Jirevocii and SARS-CoV-2 coinfection: A common feature in transplant recipients? Vaccines 8: 1-6. https://doi.org/10.3390/vaccines, 8030544 .

Du, Y.; Tu, L.; Zhu, P.; Mu, M.; Wang, R.; Yang, P.; Wang, X.; Hu, C.; Ping, R.; Hu, P.; Li, T.; Cao, F.; Chang, C.; Hu, Q.; Jin, Y. and Xu, G. (2020). Clinical features of 85 fatal cases of COVID-19 from Wuhan: A retrospective observational study. Am. J. Respir. Crit. Care Med., 201:1372-1379. https://doi.org/10.1164/rccm.202003-0543OC.

Gangneux, J.P.; Bougnoux, M.E.; Dannaoui, E.; Cornet, M and Zahar, J.R. (2020). Invasive fungal diseases during COVID-19: We should be prepared. J. Mycol. Med. https://doi.org/10.1016/j. mycmed., 2020.100971

García Clemente, M.; Hermida Valverde, T.; Leizaola-Irigoyen, O.; Enríquez Rodríguez, A.I.; Arias Guillén, M.; Telenti Asensio, M.; García Carus, E and Peláez García, T. (2021). Can SARS-CoV-2 be a risk factor for pulmonary aspergillosis? Arch. Bronconeumol. 57:72-73. https://doi.org/ 10.1016/j. Arbres., 2020.06.028.

Huang, C.; Wang, Y.; Li, X.; Ren, L.; Zhao,J.; Hu, Y.; Zhang, L.; Fan, G.; Xu, J.; Gu, X.; Cheng, Z.; Yu, T.; Xia, J.; Wei, Y.; Wu, W.; Xie, X.; Yin, W.; Li, H.; Liu, M.; Xiao, Y.; Gao, H.; Guo, L.; Xie, J.; Wang, G.; Jiang, R.; Gao, Z.; Jin, Q.; Wang, J and Cao, B. (2020). Clinical features of patients infected with 2019 novel coronavirus in Wuhan, China. Lancet, https://doi.org/ 10.1016/S0140-6736(20)30183-5.

Huang, J.; Li, H.; Lan, C.; Zou, S.; Zhang, H.; Wang, X and Weng, H. (2019). Concomitant severe influenza and cryptococcal infections: A case report and literature review. Med., (United States)., https://doi.org/ 10.1097/MD.0000000000015544. 
Hughes, S.; Troise, O.; Donaldson, H.; Mughal, N and Moore, L.S.P. (2020). Bacterial and fungal coinfection among hospitalized patients with COVID-19: A retrospective cohort study in a UK secondary-care setting. Clin. Microbiol. Infect., 26:1395-1399. https://doi.org/10.1016/ j.cmi.2020.06.025

Intra, J.; Sarto, C.; Beck, E.; Tiberti, N.; Leoni, V and Brambilla, P. (2020). Bacterial and fungal colonization of the respiratory tract in COVID-19 patients should not be neglected. Am. J. Infect. Control., https://doi.org/ 10.1016/j.ajic.2020.06.185.

Jeican, I.I.; Ini'ca, P.; Gheban, D.; Tãbãran, F.; Alua', M.; Trombitas, V.; Cristea, V.; Crivii,C.; Junie, L.M and Albu, S.(2021). COVID-19 and pneumocystis jirovecii pulmonary coinfection. The first case confirmed through autopsy. Medicina (Kaunas). 57:https://doi.org/10.3390/medicina 57040302 .

Jiang, S.(2016). Immunity against fungal infections. Immunol. Immunogenet. Insights, 8:3-6. https://doi.org/10.4137/III.S38707.

Khatri, A.; Chang, K.M.; Berlinrut, I and Wallach, F.(2021). Mucormycosis after Coronavirus disease 2019 infection in a heart transplant recipient: Case report and review of literature. J. Med. Mycol. 31:101-125. https://doi.org/10.1016/j. mycmed., 2021.101125.

Koehler, P.; Cornely, O.A.; Böttiger, B.W.; Dusse, F.; Eichenauer, D.A.; Fuchs, F.; Hallek, M.; Jung, N.; Klein, F.; Persigehl, T.; Rybniker,J.; Kochanek, M.; Böll, B and Shimabukuro-Vornhagen, A. (2020). COVID-19 associated pulmonary aspergillosis. Mycoses, 63:528-534. https://doi.org/ $10.1111 /$ myc. 13096 .

Kosmidis, C and Denning, D.W. (2015). The clinical spectrum of pulmonary aspergillosis. Thorax., https://doi.org/10.1136/thoraxjnl-2014206291 .

Lahmer, T.; Rasch, S.; Spinner, C.; Geisler, F.; Schmid, R.M and Huber, W.(2020). Invasive pulmonary aspergillosis in severe coronavirus disease 2019 pneumonia. Clin. Microbiol. Infect., https://doi.org/10.1016/ j.cmi.2020.05.032.

Lamoth, F and Calandra, T. (2018). Let's add invasive aspergillosis to the list of influenza complications. Lancet Respir. Med., https://doi.org/ $10.1016 / \mathrm{S} 2213-2600(18) 30332-1$

Lamoth, F.; Glampedakis, E.; Boillat-Blanco, N.; Oddo, M and Pagani, J.L. (2020) Incidence of invasive pulmonary aspergillosis among critically ill COVID-19 patients. Clin. Microbiol. Infect., https://doi.org/10.1016/ j.cmi.2020.07.010.

Lescure, F.X.; Bouadma, L.; Nguyen, D.; Parisey, M.; Wicky, P.H.; Behillil, S.; Gaymard, A.; Bouscambert-Duchamp, M.; Donati, F.; Le Hingrat, Q.; Enouf, V.; Houhou-Fidouh, N.; Valette, M.; Mailles, A.; Lucet, J.C.; Mentre, F.; Duval, X.; Descamps, D.; Malvy, D.; Timsit, J.F.; Lina, B.; van-der-Werf, S and Yazdanpanah, Y. (2020). Clinical and virological data of the first cases of COVID-19 in Europe: a case series. Lancet Infect. Dis., 20:697706. https://doi.org/10.1016/S1473-3099(20)30200-0.

Li, X.; Xu, S.; Yu, M.; Wang, K.; Tao, Y.; Zhou, Y.; Shi, J.; Zhou, M.; Wu, B.; Yang,Z.; Zhang, C.; Yue, J.; Zhang, Z; Renz, H.; Liu, X.; Xie, J.; Xie, M and Zhao,J.(2020). Risk factors for severity and mortality in adult COVID-19 inpatients in Wuhan. J. Allergy Clin. Immunol., 146:110-118. https://doi.org/ 10.1016/j.jaci.2020.04.006.

Mang, S.; Kaddu-Mulindwa, D.; Metz, C.; Becker, A.; Seiler, F.; Smola, S.; Maßmann, A.; Becker, S.L.; Papan, C.; Bals, R.; Lepper, P.M and Danziger, G. (2020). Pneumocystis Jirovecii Pneumonia and SARS-CoV-2 Co-Infection in newly diagnosed HIV-1 infection. Clin. Infect. Dis., 26:979-993.

Mehta, P.; McAuley, D.F.; Brown, M.; Sanchez, E.; Tattersall, R.S. and Manson, J.J. (2020). COVID-19: Consider cytokine storm syndromes and immunosuppression. Lancet, https://doi.org/10.1016/S01406736(20)30628-0.

Mehta, S and Pandey, A. (2020). Rhino-orbital mucormycosis associated with COVID-19. Cureus. https://doi.org/10.7759/cureus,10726.
Meijer, E.F.J.; Dofferhoand, A.S.M.; Meis, J.F.; Hoiting, O. and Buil, J.B. (2020). Azole-resistant COVID-19 - associated pulmonary aspergillosis in an immunocompetent host: A case report. J. Fungi, 6:1-8. https:// doi.org/10.3390/jof6020079.

Menon,A.A.; Berg, D.D.; Brea, E.J.; Deutsch,A.J.; Kidia, K.K.; Thurber, E.G; Polsky, S.B.; Yeh, T.; Duskin, J.A.; Holliday, A.M.; Gay, E.B and Fredenburgh, L.E. (2020). A case of COVID-19 and pneumocystis jirovecii coinfection. Am. J. Respir. Crit. Care Med., https://doi.org/10.1164/rccm. 2020 03-0766LE.

Metlay, J.P.; Waterer, G.W.; Long,A.C.; Anzueto, A.; Brozek, J.; Crothers, K.; Cooley, L.A.; Dean, N.C.; Fine, M.J.; Flanders, S.A.; Griffin, M.R.; Metersky, M.L.; Musher, D.M.; Restrepo, M.I and Whitney, C.G. (2019). Diagnosis and treatment of adults with community-acquired pneumonia. An official clinical practice guideline of the American Thoracic Society and Infectious Diseases Society of America. Am. J. Respir. Crit. Care Med., 200:e45-e67. https://doi.org/10.1164/rccm.201908-1581st.

Morena, V.; Milazzo, L.; Oreni, L.; Bestetti, G.; Fossali, T.; Bassoli, C.; Torre, A.; Cossu, M.V.; Minari, C.; Ballone, E.; Perotti, A.; Mileto, D.; Niero, F.; Merli, S.; Foschi,A.; Vimercati, S.; Rizzardini, G.; Sollima, S.; Bradanini, L.; Galimberti, L.; Colombo, R.; Micheli, V.; Negri, C.; Ridolfo, A.L.; Meroni, L.; Galli, M.; Antinori, S and Corbellino, M.(2020). Off-label use of tocilizumab for the treatment of SARS-CoV-2 pneumonia in Milan, Italy. Eur. J. Intern. Med., 76:36-42. https://doi.org/10.1016/j.ejim.2020.05.011.

Nasir, N.; Farooqi, J.; Mahmood, S.F and Jabeen, K. (2020). COVID-19-associated pulmonary aspergillosis (CAPA) in patients admitted with severe COVID-19 pneumonia: An observational study from Pakistan. Mycoses, 63:766-770. https://doi.org/10.1111/myc.13135.

Nasri, E.; Shoaei, P.; Vakili, B.; Mirhendi, H.; Sadeghi, S.; Hajiahmadi, S.; Sadeghi, A.; Vaezi, A.; Badali, H and Fakhim, H. (2020). Fatal invasive pulmonary aspergillosis in COVID-19 patient with acute myeloid leukemia in iran. Mycopathologia, 185:1077-1084. https://doi.org/10.1007/ s1 1046-020-00493-2.

Netea, M.G; Joosten, L.A.B.; Van Der Meer, J.W.M.; Kullberg, B.J and Van De Veerdonk, F.L.(2015). Immune defence against Candida fungal infections. Nat. Rev. Immunol., https://doi.org/10.1038/nri3897.

Nori, P.; Cowman, K.; Chen, V.; Bartash, R.; Szymczak, W.; Madaline, T.; Punjabi Katiyar, C.; Jain, R.; Aldrich, M.; Weston, G.; Gialanella, P.; Corpuz, M.; Gendlina, I and Guo, Y. (2021). Bacterial and fungal coinfections in COVID-19 patients hospitalized during the New York City pandemic surge. Infect. Control Hosp. Epidemiol., 42:84-88. https://doi.org/ 10.1017/ice.2020.368.

Pappas, P.G.; Lionakis, M.S.; Arendrup, M.C.; Ostrosky-Zeichner, Land Kullberg, B.J. (2018). Invasive candidiasis. Nat. Rev. Dis. Prim., 4. https:// doi.org/10.1038/nrdp.2018.26.

Peng, J.; Wang, Q.; Mei, H.; Zheng, H.; Liang, G.; She, X and Liu, W. (2021). Fungal co-infection in COVID-19 patients: Evidence from a systematic review and meta-analysis. Aging (Albany. NY), 13:7745-7757. https://doi.org/10.18632/aging.202742.

Perlin, D.S. (2015). Echinocandin resistance in candida. Clin. Infect. Dis., 61:S612-S617. https://doi.org/10.1093/cid/civ791.

Posteraro, B.; Torelli, R.; Vella, A.; Leone, P.M.; De Angelis, G.; De Carolis, E.; Ventura, G.; Sanguinetti, M and Fantoni, M. (2020). Pan-echinocandinresistant candida glabrata bloodstream infection complicating COVID-19: A fatal case report. J. Fungi, 6:1-11. https://doi.org/ 10.3390/jof6030163.

Prattes, J.; Valentin, T.; Hoenigl, M.; Talakic, E.; Reisinger, A.C and Eller, P. (2021). Invasive pulmonary aspergillosis complicating COVID-19 in the ICU - A case report. Med. Mycol. Case Rep., 31:2-5. https://doi.org/ 10.1016/j.mmcr.2020.05.001.

Rawson, T.M.; Moore, L.S.P.; Zhu, N.; Ranganathan, N.; Skolimowska, K.; Gilchrist, M.; Satta, G.; Cooke, G and Holmes, A. (2020). Bacterial and fungal coinfection in individuals with coronavirus: A rapid review to support COVID-19 antimicrobial prescribing. Clin. Infect. Dis., 71:24592468. https://doi.org/10.1093/cid/ciaa530. 
Rutsaert, L.; Steinfort, N.; Van Hunsel, T.; Bomans, P.; Naesens, R.; Mertes, H.; Dits, H and Van Regenmortel, N.(2020). COVID-19: Associated invasive pulmonary aspergillosis. Ann. Intensive. Care, https://doi.org/ 10.1186/s13613-020-00686-4

Salehi, M.; Ahmadikia, K.; Mahmoudi, S.; Kalantari, S.; Jamalimoghadamsiahkali, S.; Izadi, A.; Kord, M.; Dehghan Manshadi, S.A.; Seifi, A.; Ghiasvand, F.; Khajavirad, N.; Ebrahimi, S.; Koohfar, A.; Boekhout, T and Khodavaisy, S. (2020). Oropharyngeal candidiasis in hospitalised COVID-19 patients from Iran: Species identification and antifungal susceptibility pattern. Mycoses, 63:771-778. https://doi.org/10.1111/myc.13137.

Santana, M.F.; Pivoto, G.; Alexandre, M.A.A.; Baía-Da-silva, D.C.; Borba, M.G. da S; Val, FA.; Brito-Sousa, J.D; Melo, G.C.; Monteiro, W.M.; Souza, J.V.B.; Pinheiro, S.B.; Ferreira, L.C.L.; Naveca, F.G; Nascimento, V.A.; Corado, A.L.G. Hajjar, L.A.; Neto, J.R.S.; Siva, G.A.V.; Pasqualotto, A.C and Lacerda, M.V.G.(2020). Confirmed invasive pulmonary aspergillosis and COVID19: The value of postmortem findings to support antemortem management. Rev. Soc. Bras. Med. Trop., 53:1-4. https://doi.org/ 10.1590/0037-8682-0401-2020.

Sari, A.P.; Darnindro, N.; Yohanes, A and Mokoagow, M.I. (2021). Role of tocilizumab for concomitant systemic fungal infection in severe COVID-19 patient: Case report. Medicine (Baltimore), 100:e25173. https://doi.org/10.1097/MD.0000000000025173.

Schauwvlieghe,A.F.A.D.; Rijnders, B.J.A.; Philips, N.; Verwijs, R.; Vanderbeke, L.; Van Tienen, C.; Lagrou, K.; Verweij, P.E.; Van de Veerdonk, F.L.; Gommers, D.; Spronk, P.; Bergmans, D.C.J.J.; Hoedemaekers, A.; Andrinopoulou, E.R.; van den Berg, C.H.S.B.; Juffermans, N.P.; Hodiamont, C.J.; Vonk, A.G.; Depuydt, P.; Boelens, $\mathbf{J}$ and Wauters, J. (2018). Invasive aspergillosis in patients admitted to the intensive care unit with severe influenza: A retrospective cohort study. Lancet Respir. Med., 6:782-792. https:/ /doi.org/10.1016/S2213-2600(18)30274-1.

Seitz, T.; Hoepler, W.; Weseslindtner, L.; Aberle, J.H.; Aberle, S.W.; PuchhammerStoeckl, E.; Baumgartner, S.; Traugott, M.; Karolyi, M.; Pawelka, E.; Niculescu, I.; Friese, E.; Neuhold, S.; Stahl, D.; Madl, C.; Zoufaly, A.; Wenisch, C and Laferl, H. (2020). Successful management of the first reported case in Austria of COVID-19 with ARDS. Infection, 48:647-651. https:// doi.org/10.1007/s15010-020-01458-9.

Shah,A.S.; Heidari,A.; Civelli, V.F.; Sharma, R.; Clark, C.S.; Munoz,A.D.; Ragland, A.S and Johnson, R.H. (2020). The coincidence of 2 epidemics, Coccidioidomycosis and SARS-CoV-2: A case report. J. Investig. Med. High Impact Case Reports, 8. https://doi.org/10.1177/2324709620 930540 .

Silva, L.N.; de Mello, T.P.; de Souza Ramos, L.; Branquinha, M.H and dos Santos, A.L.S.(2019). Current challenges and updates on the therapy of fungal infections. Curr. Top. Med. Chem., 19:495-499. https://doi.org/ $10.2174 / 156802661907190531093808$.

Trovato, L.; Calvo, M.; Migliorisi, G.; Astuto, M.; Oliveri, F and Oliveri, S. (2021) Fatal VAP-related pulmonary aspergillosis by Aspergillus niger in a positive COVID-19 patient. Respir. Med. Case Reports, 32. https:// doi.org/10.1016/j.rmcr.2021.101367.

Van Arkel,A.L.E.; Rijpstra, T.A.; Belderbos, H.N.A.; van Wijngaarden, P.; Verweij, P.E and Bentvelsen, R.G. (2020). COVID-19: Associated pulmonary aspergillosis. Am. J. Respir. Crit. Care Med., https://doi.org/10.1164/ rccm.202004-1038LE.
Ventoulis, I.; Sarmourli, T.; Amoiridou, P.; Mantzana, P.; Exindari, M.; Gioula, G and Vyzantiadis, T.A. (2020). Bloodstream infection by saccharomyces cerevisiae in two COVID-19 patients after receiving supplementation of saccharomyces in the icu. J. Fungi, 6:1-7. https://doi.org/10.3390/ jof6030098.

Waizel-Haiat, S.; Guerrero-Paz, J.A.; Sanchez-Hurtado, L.; Calleja-Alarcon, S and Romero-Gutierrez, L. (2021). A case of fatal rhino-orbital mucormycosis associated with new onset diabetic ketoacidosis and COVID-19. Cureus. https://doi.org/10.7759/cureus.13163.

Wang, H.; Wang, Y.; Yang, Q.W.; Ni, Y.X.; Lin, L.K.; Luo, Y.P.; Sun, Z.Y.; Li, M.; Wu, W.J.; Zhang, Q.Q.; Su, D.H.; Yu, H.; Kang, M.; Xu, H.P.; Liu, W.; Yang, Q.; Jian, C.; Guo, L.N.; Yang, W.H.; Xiao, M.; Hsueh, P.R and Xu, Y.C. (2020). Anational survey on fungal infection diagnostic capacity in the clinical mycology laboratories of tertiary care hospitals in China. J. Microbiol. Immunol. Infect., 53:845-853. https://doi.org/10.1016/ j.jmii.2020.03.016

Wang, J.; Yang, Q.; Zhang, P.; Sheng, J.; Zhou, J.; Qu, T and Qu, T. (2020). Clinical characteristics of invasive pulmonary aspergillosis in patients with COVID-19 in Zhejiang, China: A retrospective case series. Crit. Care, 24. https://doi.org/10.1186/s13054-020-03046-7.

White, P.; Price, J and Backx, M.(2018). Therapy and Management of Pneumocystis jirovecii Infection. J. Fungi, 4:127. https://doi.org/ $10.3390 /$ jof 4040127 .

Wu, Y.C.; Chen, C.S and Chan, Y.J. (2020). The outbreak of COVID-19: An overview. J. Chinese Med. Assoc., https://doi.org/ 10.1097/JCMA.0000000000000270

Yang, X.; Yu, Y.; Xu, J.; Shu, H.; Xia, J.; Liu, H.; Wu, Y.; Zhang, L.; Yu, Z; Fang, M.; Yu,T.; Wang, Y.; Pan, S.; Zou, X.; Yuan, S and Shang, Y. (2020). Clinical course and outcomes of critically ill patients with SARS-CoV-2 pneumonia in Wuhan, China: A single-centered, retrospective, observational study. Lancet Respir. Med., 8:475-481. https://doi.org/10.1016/ S2213-2600(20)30079-5

Yap, F.H.Y.; Gomersall, C.D.; Fung, K.S.C.; Ho, P.L.; Ho, O.M.; Lam, P.K.N.; Lam, D.T.C.; Lyon, D.J and Joynt, G.M. (2004). Increase in methicillin-resistant Staphylococcus aureus acquisition rate and change in pathogen pattern associated with an outbreak of severe acute respiratory syndrome. Clin. Infect. Dis., 39:511-516. https://doi.org/10.1086/ 422641

Yuki, K.; Fujiogi, M and Koutsogiannaki, S. (2020). COVID-19 pathophysiology: A review. Clin. Immunol., https://doi.org/10.1016/j.clim.2020. 108427 .

Zhang, L.; Sun, W.; Wang, Y.; Wang, X.; Liu, Y.; Zhao, S.; Long, D.; Chen, Land Yu, L. (2020). Clinical course and mortality of stroke patients with coronavirus disease 2019 in Wuhan, China. Stroke, 2674-2682. https://doi.org/10.1161/STROKEAHA.120.030642.

Zhu, N.; Zhang, D.; Wang, W.; Li, X.; Yang, B.; Song, J.; Zhao, X.; Huang, B.; Shi, W.; Lu, R.; Niu, P.; Zhan, F.; Ma, X.; Wang, D.; Xu, W.; Wu, G; Gao, G.F and Tan,W. (2020). A novel coronavirus from patients with pneumonia in China, 2019. N. Engl. J. Med., https://doi.org/10.1056/NEJMoa2001017.

Zhu, X.; Ge, Y.; Wu, T.; Zhao, K.; Chen,Y.; Wu, B.; Zhu, F.; Zhu, B and Cui, L.(2020). Co-infection with respiratory pathogens among COVID-2019 cases. Virus Res., 285. https://doi.org/10.1016/j.virusres.2020.198005. 